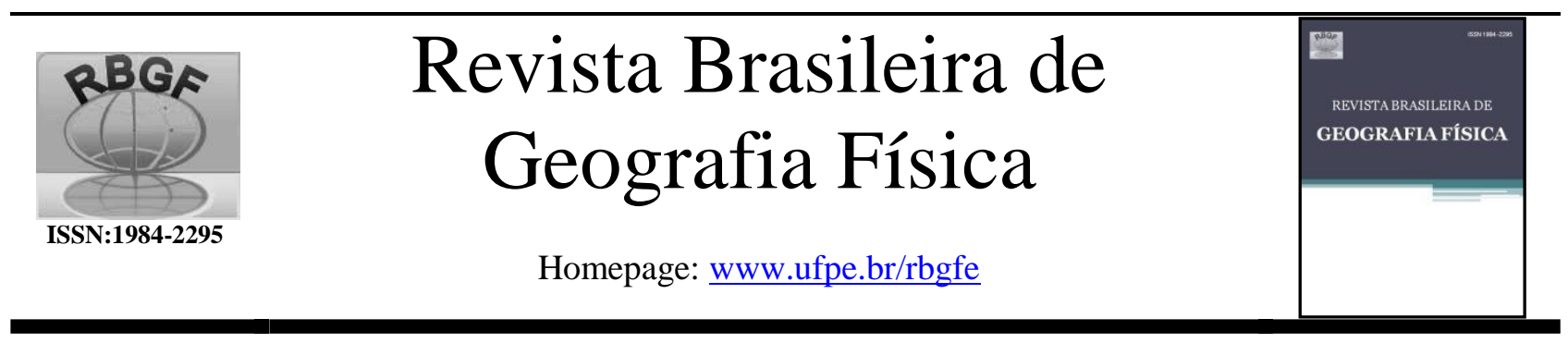

\title{
Comportamento da Precipitação Pluviométrica nas Porções Alta e Média da Bacia Hidrográfica do Rio Canoas/SC: Análise Temporal de 1986-2016
}

\author{
Andrea Cristina Conceição Lemos ${ }^{1}$, Dejanira Luderitz Saldanha ${ }^{2}$, Álvaro Luiz Mafra ${ }^{3}$
}

${ }^{1}$ Professora do Instituto Federal Sul Rio-Grandense - Campus Charqueadas, Charqueadas- RS, Doutoranda no Programa de Pós Graduação em Geografia, Porto Alegre-RS, Universidade Federal do Rio Grande do Sul - UFRGS. andrealemos.geo@ gmail.com ${ }^{2}$ Professora Doutora no Programa de Pós Graduação em Geografia, Porto Alegre-RS, Universidade Federal do Rio Grande do Sul - UFRGS, dejanira.saldanha@ufrgs.br ${ }^{3}$ Professor Titular do Departamento de Solos e Recursos Naturais, Lages-SC, Universidade do Estado de Santa Catarina - UDESC alvaro.mafra@ udesc.br

\section{Artigo submetido em 26/12/2017 e aceite em 28/05/2018}

\section{R E S U M O}

Este estudo identificou os principais sistemas atmosféricos que influenciam nas precipitações pluviométricas no alto e médio trecho da bacia hidrográfica do rio Canoas durante os anos de 1986-2016. Foram manipulados dados anuais e mensais de 15 estações pluviométricas localizadas em quatorze municípios da região central do estado de Santa Catarina (Brasil). Os dados de médias pluviométricas foram obtidos das séries de dados históricos e espacializadas através do método de interpolação IDW. Por ser uma região de transição atmosférica sofre influência de diversos fatores ambientais. Na área de estudo foi possível observar a influência de três sistemas atmosféricos principais na precipitação: o sistema de monção, o qual eleva os valores da precipitação no leste da área de estudo principalmente nos municípios de Urubici e Bom Retiro; os Complexos Convectivos de Mesoescala (CCMs), que elevam os padrões de precipitação no centro-oeste principalmente nos meses de primavera; e por fim as frentes vindas do sul, as quais influênciam no total das precipitações nos meses de inverno. A espacialização desses padrões e compreensão das dinâmicas presentes na área são importantes para o monitoramento e identificação de anomalias no comportamento pluviométrico da região, auxiliando tanto na agricultura como no planejamento/aproveitamento territorial.

Palavras-chave: bacia hidrográfica - Rio Canoas - precipitação - comportamento pluviométrico.

\section{Rainfall distribution in the upper and middle portions of the Canoas Watershade / SC: 1986-2016 Temporal analysis}

\begin{abstract}
A B S T R A C T
This study identified the main atmospheric systems that influence rainfall in the upper and middle portions of the Canoas river watershed during the years 1986-2016. Annual and monthly data were analyzed from 15 pluviometric stations located in fourteen municipalities in the central region of Santa Catarina state (Brazil). The average rainfall data were obtained from the historical data series and spatialized using the IDW interpolation method. Being a region of atmospheric transition, it is influenced by several environmental factors. In the study area, it was possible to observe the influence of three main atmospheric systems on the precipitation: the monsoon system, which increases precipitation values in the east side of the study area, mainly in the municipalities of Urubici and Bom Retiro; the Mesoscale Convective Complexes (CCMs), which raises rainfall patterns in the midwest region, especially in the spring months; and finally the southern fronts, which influences the total precipitation in the winter months. The spatialization of these patterns and understanding of the dynamics present in the area are important for the monitoring and identification of anomalies in the pluviometric distribution in the region, helping both in agriculture and in the planning / territorial utilization.
\end{abstract}

Keywords: watershed - Canoas River - precipitation - rainfall distribution. 


\section{Introdução}

No Brasil a precipitação é uma das variáveis meteorológicas mais importantes nos estudos climáticos. Tal importância deve-se às consequências que chuvas intensas podem ocasionar para os setores produtivos da sociedade, especialmente na forma de alagamentos, assoreamento dos rios e quedas de barreiras (Amorin et al., 2008).

Maier et al. (2016) ressalta a importância da quantificação da precipitação quando diz:

"Entre os principais ciclos do balanço térmico e hídrico de um regime climático, o ciclo hidrológico é um dos mais importantes para a produtividade dos ecossistemas pelo papel da água na manutenção da cadeia alimentar. Onde as precipitações são a maior porcentagem da recarga de água de um ecossistema, tornando-as uma variável reguladora da produtividade primária e secundária. Frente à importância da água, a compreensão dos principais padrões da distribuição espacial e temporal da precipitação pode minimizar a vulnerabilidade humana por meio da gestão ambiental sustentável." Dentre os elementos climatológicos, a precipitação é o que diretamente reflete a instabilidade do tempo e a intensidade com que essas variações se processam, podendo ainda ser considerada como um dos principais fatores responsáveis pelo desenvolvimento dos sistemas morfogenéticos tropicais (Bigarella et al., 2007). Monteiro (1976) justifica o uso das informações de precipitação por este representar "o output mais significativo da atuação dos sistemas atmosféricos intertropicais e mesmo em seus totais anuais, poderá refletir o processo genético da circulação regional". Destacase que a chuva nos ambientes tropicais e subtropicais representa o principal aporte atmosférico de água, que constitui recurso essencial para a vida e para as atividades humanas. Assim, do ponto de vista geográfico, calor e umidade desencadeiam uma série de processos, que levam à formação de solos, afetam a estrutura e formas de relevo, condicionam os recursos hídricos, além de regularem o crescimento, desenvolvimento e distribuição das plantas e animais, inclusive repercutindo nas atividades antrópicas (Rossato, 2011).

Segundo Sant'Anna Neto (1998), a relação entre clima e organização do espaço depende do grau de desenvolvimento econômico e tecnológico de cada sociedade em particular. No que tange a agricultura, há que se considerar que o papel exercido pelo clima na organização das áreas rurais e urbanas embora diferente são igualmente relevantes. Em áreas urbanas ou em processo de urbanização percebe-se a modificação do clima original em função da expansão das edificações. Também a impermeabilização do solo é identificada como um fator de mudança no microclima, principalmente nos grandes centros. Nas áreas rurais, a variabilidade sazonal e as excepcionalidades climáticas afetam a produção agrícola. Dessa forma, o reconhecimento de padrões climáticos pode auxiliar a planejar a produção ao mesmo tempo em que proporciona maior garantia de produção em condições de vulnerabilidade.

A região sul do país apresenta grandes contrastes nos regimes de precipitação e temperatura. Parte deles deve-se a situação geográfica (latitudes médias) e de relevo, onde, as maiores precipitações associam-se à ascensão sobre a barreira topográfica. No caso do estado de Santa Catarina, o clima é caracterizado conforme Köppen em mesotérmico úmido (sem estação seca) - Cf, com dois subtipos: Cfa com temperatura média no mês mais frio inferior a $18^{\circ} \mathrm{C}$ e média do mês mais quente acima de $22^{\circ} \mathrm{C}$, com verões quentes, geadas pouco frequentes e tendência de concentração de chuvas nos meses de verão, contudo sem estação seca definida; O subtipo Cfb se caracteriza pela temperatura média no mês mais frio abaixo de $18^{\circ} \mathrm{C}$, com verões frescos e temperatura média do mês mais quente abaixo de $22^{\circ} \mathrm{C}$, sem estação seca definida (Pandolfo, et al., 2002).

Para o planalto catarinense, localizado no centro da região sul, percebe-se como fatores determinantes da precipitação pluvial, tanto a influência do sistema de monção, como das chuvas concentradas ocasionadas pelos Complexos Convectivos de Mesoescala (CCMs), que se formam no oeste do estado principalmente nos meses de primavera e verão (Vera, et al., 2006). Os CCMs movem-se para leste a partir de sua fonte no norte da Argentina e Paraguai para afetar o sudoeste do Brasil e Uruguai com intensas precipitações (Velasco e Fritsch, 1987; Scolar e Figueiredo, 1990). Estes complexos foram reconhecidos inicialmente na região central dos Estados Unidos. No entanto, muitos estudos surgiram em várias regiões do planeta relatando a ocorrência desses sistemas, inclusive em latitudes médias na América do Sul. Ainda hoje, apesar dos avanços na meteorologia, os CCMs são de difícil previsibilidade, já que esses eventos não estão associados ao tipo de sistema meteorológico, como frentes frias ou linhas de instabilidade. Sua gênese e desenvolvimento são resultantes da umidade disponível na atmosfera, em baixos níveis; da circulação do ar superior, em altos níveis; e da circulação local (Maddox, 1980). Estes complexos ocorrem, sobretudo, na metade quente do ano, e produzem grande variedade de fenômenos meteorológicos adversos, tais como tornados, granizo, fortes rajadas de vento, enchentes, inundações e tempestades elétricas (Maddox, 1980; Maddox, 1983). 
O planalto catarinense é uma região caracteristicamente rural tendo como sua maior área urbana a cidade de Lages com entorno de 156.727 habitantes (IBGE, 2010). A área selecionada para a presente análise, localiza-se no alto e médio trecho da bacia hidrográfica do rio Canoas. Esta região possui distribuição pluviométrica uniforme, onde as médias anuais ficam aproximadamente entre 1200 a $2000 \mathrm{~mm}$. O relevo caracteriza-se por colinas e morros de interflúvios amplos, não exercendo grande influência na distribuição pluviométrica. Entre os fenômenos atmosféricos que influenciam a precipitação da região cita-se a passagem de sistemas frontais responsáveis por parte dos totais pluviométricos (Oliveira, 1986). A trajetória desses sistemas está intimamente ligada ao posicionamento e intensidade do jato subtropical da América do Sul, conforme ressaltam Browing (1986) e Kousky e Cavalcanti (1984). O estado de Santa Catarina também sofre influência dos cavados invertidos, os quais, segundo Fernandes (1996) são mais frequentes no verão e primavera no hemisfério Sul, com orientação na direção noroestesudeste (NO-SE), paralelamente à superfície frontal, e são responsáveis pelo desenvolvimento de tempo severo sobre as regiões afetadas. Nos anos de ocorrência do fenômeno El Niño-Oscilação Sul (ENOS) esta região também registra anomalias positivas de precipitação. Ropelewski e Halpert (1987) e Kousky e Ropelewski (1989) afirmam que esta relação se dá nos meses de novembro a fevereiro. Ainda nesta região, há influência dos complexos convectivos de mesoescala (CCM), bem como a ocorrência de ciclogêneses e frontogêneses.

As referências que abordam variabilidade pluvial estão baseadas no conceito de variabilidade expresso por Sorre, que se caracteriza pela amplitude dos desvios entre valores sucessivos de um elemento do clima; e no conceito adotado pela Organização Meteorológica Mundial (OMM), que estabelece a variabilidade climática como a maneira pela qual os parâmetros climáticos variam no interior de um determinado período de registro (Ely, 2006). A investigação das flutuações pluviométricas interanuais é realizada pela identificação dos anos padrão, técnica desenvolvida por Monteiro (1971) para determinar a duração e a sequência das condições chuvosas e secas e a frequência dos principais sistemas atmosféricos responsáveis pela gênese das chuvas sobre um recorte territorial. Associa-se ao procedimento anterior, para complementação, a estatística descritiva, isto é, cálculo de medidas de tendência central como a média e medidas de variabilidade ou dispersão (desvio padrão, variância).

A demanda dos conjuntos de dados espaciais, em forma digital, tem aumentado muito nos últimos anos. Esta demanda tem sido fornecida em função do amadurecimento de tecnologias computacionais, capacitando uma variedade de modelos de recursos naturais, hidrológicos, agrícolas e sistemas especializados, gerenciáveis a partir de sistema de informação geográfica (SIG). Os SIGs são destinados à manipulação de dados georreferenciados, e com a utilização de técnicas de espacialização, podem verificar a forma como as precipitações se distribuem no espaço, bem como, associar diferentes fatores ambientais. Estas técnicas conforme Caruso e Quarta (1998) permitem abranger grandes regiões, com agilidade e precisão. Diante do exposto, o objetivo do trabalho foi realizar a espacialização dos dados de chuvas na porção alta e média bacia do Canoas, no Planalto Catarinense.

\section{Material e métodos}

O estudo foi desenvolvido no trecho alto e médio da bacia do Canoas, circunscrita entre as coordenadas planas UTM $6985051 \mathrm{~N}$ e $6886547 \mathrm{~S}-$ $500646 \mathrm{~W}$ e $669057 \mathrm{~W}$ e composta por 17 municípios: Urubici, Bom Retiro, Rio Rufino, Painel, Bocaina do Sul, Lages, Palmeira, Otacílio Costa, Capão Alto, Campo Belo do Sul, São José do Cerrito, Correia Pinto, Ponte Alta, Curitibanos, Vargem, Brunópolis e São Cristóvão do Sul.

Essa região apresenta substrato formado por rochas sedimentares gonduânicas e rochas magmáticas recentes da Formação Serra Geral. O relevo local varia em relação à altimetria, entre 679 e 1818 metros, que agrupam duas morfoesculturas: o planalto meridional e depressão periférica. Esses aspectos de relevo e altimetria foram considerados na escolha das estações meteorológicas (Figura 1).

A análise temporal do comportamento pluviométrico foi baseada em dados de precipitação das séries históricas pluviométricas, obtidas na Agência Nacional de Águas - ANA no módulo Hidroweb. Também foram utilizadas médias mensais para um período de 31 anos (1986-2016), período comum a todas as estações e que configura uma normal climatológica (30 anos) para análise. Esses dados foram filtrados devido à ausência de valores em alguns deles. Em algumas estações havia ausência de décadas inteiras. Desta forma foram consideradas satisfatórias as localidades onde a falta de dados fosse mínima, por isso, a escolha criterizou a melhor distribuição espaço-temporal. Realizada a triagem dos dados selecionou-se 15 estações (Tabela 1) distribuídas na bacia hidrográfica do Rio Canoas. Após a interpolação dos dados foi realizado um recorte para os trechos alto e médio da bacia hidrográfica para análise no presente trabalho. 
Tabela 1. Estações meteorológicas selecionadas, sua localização e altitude.

\begin{tabular}{llllll} 
Responsável & $\begin{array}{l}\text { Código da } \\
\text { Estação }\end{array}$ & Nome da Estação & $\begin{array}{l}\text { Latitude } \\
\text { (decimais) }\end{array}$ & $\begin{array}{l}\text { Longitude } \\
\text { (decimais) }\end{array}$ & $\begin{array}{l}\text { Altitude } \\
\text { (metros) }\end{array}$ \\
\hline ANA & 2849021 & Urubici & $-27,9886$ & $-49,5775$ & 997 \\
ANA & 2750007 & Painel & $-27,9222$ & $-50,0992$ & 1196 \\
ANA & 2749031 & Vila Canoas & $-27,8042$ & $-49,78$ & 900 \\
ANA & 2749035 & Bocaina do Sul & $-27,7464$ & $-49,945$ & 900 \\
ANA & 2749009 & Rio Bonito & $-27,7039$ & $-49,8472$ & 900 \\
ANA & 2751001 & Anita Garibaldi & $-27,6922$ & $-51,1294$ & 800 \\
ANA & 2750020 & São José do Cerrito & $-27,6606$ & $-50,5831$ & 920 \\
ANA & 2750008 & Passo Caru & $-27,5417$ & $-50,8569$ & 720 \\
ANA & 2750011 & Ponte Alta do Sul & $-27,4819$ & $-50,385$ & 840 \\
ANA & 2750012 & Ponte do Rio Antinhas & $-27,3453$ & $-50,4358$ & 940 \\
ANA & 2750009 & Passo Marombas & $-27,3339$ & $-50,7533$ & 829 \\
ANA & 2750010 & Ponte Alta do Norte & $-27,1611$ & -504689 & 980 \\
ANA & 2750022 & Ponte Alta do Norte - & $-27,1208$ & $-50,4567$ & 960 \\
& & CIFSUL & & & \\
ANA & 2650019 & Lebon Regis & $-26,93$ & $-50,6881$ & 1000 \\
INMET & 2750005 & Lages & $-27,8083$ & $-50,3283$ & 937 \\
\hline
\end{tabular}

Fonte: ANA, INMET. Organização: LEMOS, 2017.

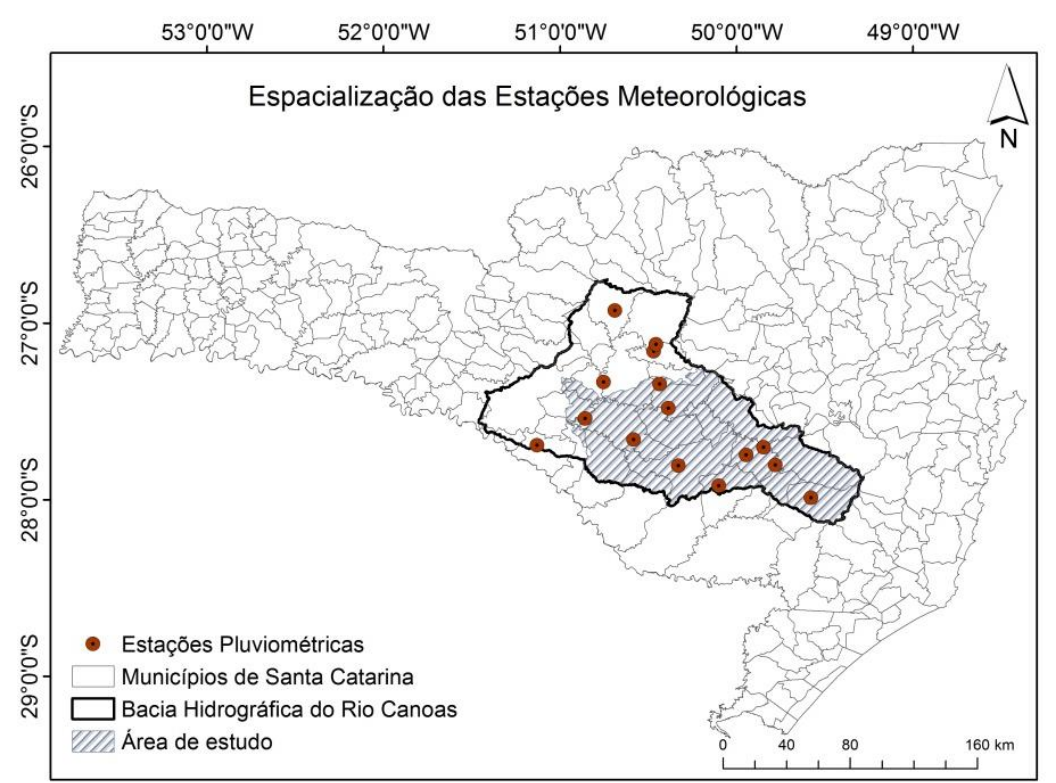

Figura 1. Localização das estações meteorológicas utilizadas no estudo. Fonte: Agência Nacional de Águas -

ANA (2016).

Para isto foram utilizadas as séries temporais anuais e mensais das quinze estações pluviométricas, referentes ao período de 19862016.

Para o cálculo da interpolação do valor de um ponto com base no método IDW, foi utilizada a Equação 1 melhorar (Marcuzzo, Andrade e Melo, 2011):

$$
Z(X)=\frac{\sum_{i=1}^{n} \omega_{i} Z(X)}{\sum_{i=1}^{n} \omega_{i}} \quad \text { Eq. } 1
$$

Onde, $\mathrm{Z}(\mathrm{X})$ é o valor do ponto que se deseja interpolar; $n$ é a quantidade de pontos próximos utilizados na interpolação do ponto $\mathrm{X} ; \mathrm{Z}(\mathrm{Xi})$ é o valor do ponto $\mathrm{Xi}$; e $\omega$ i é o peso do valor de $\mathrm{Xi}$ sobre o ponto X. Para se determinar $\omega \mathrm{i}$, foi utilizada a 
Equação 2:

$$
\omega_{\mathrm{i}}=\frac{1}{\mathrm{~h}\left(\mathrm{X}, \mathrm{X}_{\mathrm{i}}\right)^{\mathrm{p}}}
$$

Sendo, $\mathrm{h}(\mathrm{X}, \mathrm{Xi})$ a distância entre o ponto $\mathrm{X}$ e o ponto Xi; e p o parâmetro de potência, igual a dois.

\section{Análise Estatística}

A análise da variabilidade espacial e temporal para definição de regimes pluviométricos foi baseada em valores médios. A partir do tratamento das séries temporais das estações meteorológicas, foi possível calcular para cada um dos postos, as médias mensais e anuais, para o período de dados.

Considerando as mesmas escalas de tempo, foram mensurados os desvios padrão e coeficientes de variação para as séries. Este procedimento foi realizado no programa Excel 2010.

\section{Resultados e discussão}

As médias anuais das estações analisadas na série de 31 anos demonstram (Figura 2) que no alto e médio rio Canoas a variação pluviométrica varia entre 1258 a 1685 mm, com baixa dispersão, evidenciada pelo coeficiente de variação de 7,88\% e desvio padrão de $122,3 \mathrm{~mm}$. Também é possível identificar, ainda no gráfico 1, que duas estações apresentaram valores abaixo do desvio padrão, Lages e Rio Bonito. Estas estações apresentaram vazio na sua série de dados. A de Lages apresenta ausência de cinco anos (1986, 1987, 1990, 2015, 2016) e nos anos de 2001 e 2014 os valores são muito abaixo da média de $1350 \mathrm{~mm}$ (ano). No ano de 2001 o valor da precipitação é de $487 \mathrm{~mm}$ e no ano de 2014 de $609 \mathrm{~mm}$.

Já a estação Rio Bonito apresenta ausência de dois anos completos (1993 e 1994) e valores abaixo da média $(1358,6 \mathrm{~mm})$ nos anos de 1991 $(331,8 \mathrm{~mm}), 1992(18,5 \mathrm{~mm})$ e $1995(653,7 \mathrm{~mm})$. Estes vazios na série de dados das estações de Lages e Rio Bonito justificam as áreas com valores inferiores ao desvio padrão da média anual.

A média pluviométrica da região dentro da série histórica analisada é de 1552,3 mm. Em função das condições atmosféricas como a influência do sistema de monção nos meses de verão, dos complexos convectivos de mesoescala nos meses de primavera e as frentes vindas do sul nos meses de inverno, sob estas condições, esta região possui chuvas bem distribuídas ao longo do ano sem registro de estação seca.

A espacialização dos dados, representada na Figura 3, foi realizada no software ArcGis 10.2.2 a partir do método de interpolação $I D W$, o qual permitiu preencher as áreas sem dados.

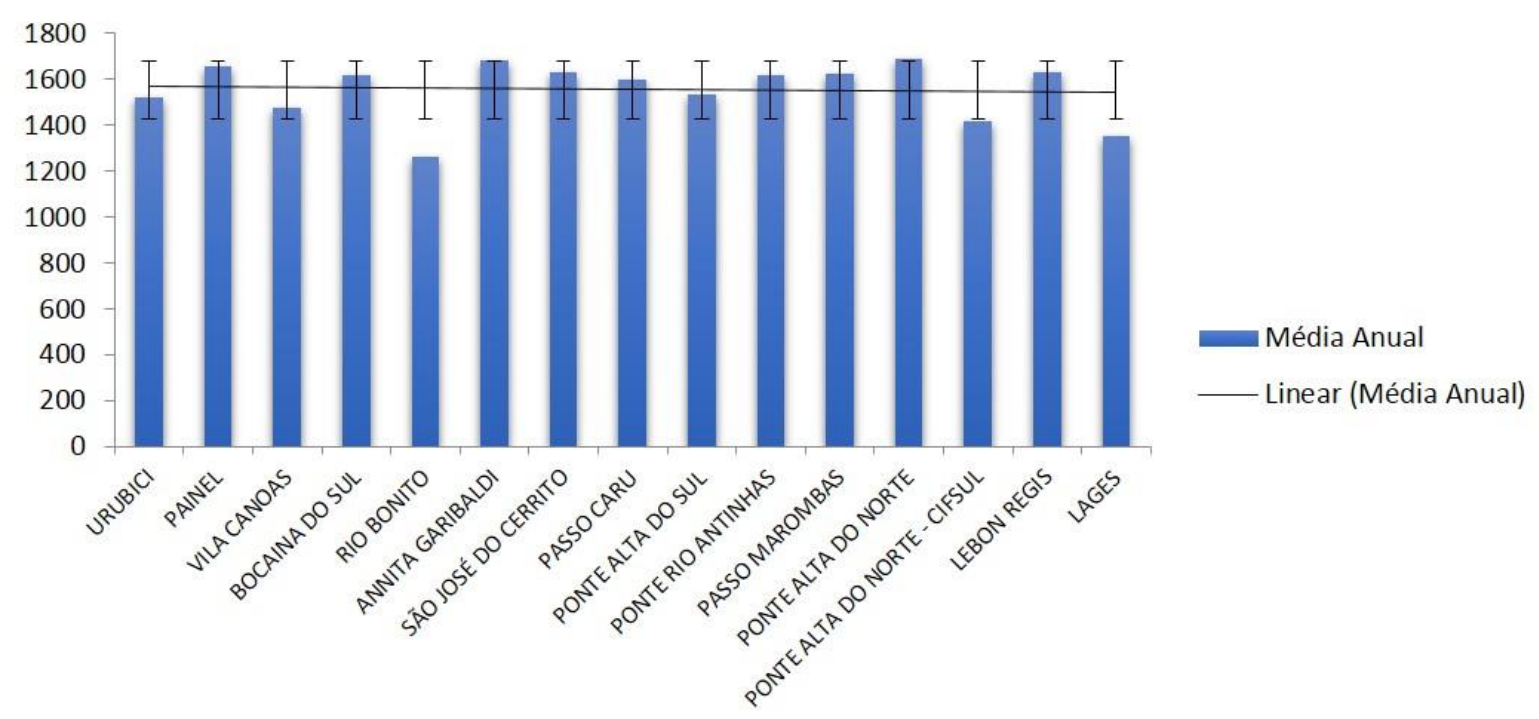

Figura 2. Média anual das estações pluviométricas do alto e médio rio Canoas (1986-2016). 
A precipitação média anual entre 19862016 varia de $1350 \mathrm{~mm}$ a $1656 \mathrm{~mm}$, sendo que os maiores valores da precipitação ocorrem na região oeste da bacia hidrográfica e também nos municípios de Painel e Bocaina do Sul, que constitui região de relevo mais elevado no centro da área de estudo. Embora haja valores relativamente altos de evaporação no sul do Brasil em todas as estações do ano, a maior contribuição à água que precipita provém do transporte de umidade vinda do norte/nordeste. Segundo Grimm (2009) há duas fontes de vapor de água disponíveis para o sul do Brasil: o oceano Atlântico e a faixa tropical do continente. Nos meses de verão, parte do transporte de vapor dos trópicos para sudeste dirige-se para o sul do Brasil e outras áreas do sudeste da América do Sul, e outra parte converge na região da ZCAS com o fluxo proveniente do oceano Atlântico, que pouco avança sobre o continente. No inverno, o fluxo de umidade que atinge o Sul origina-se no oceano Atlântico, entre $10^{\circ}$ e $20^{\circ} \mathrm{S}$, como um fluxo de oeste que se desvia para sudeste após penetrar profundamente no continente, coerente com o deslocamento para oeste da alta subtropical do Atlântico Sul.

O ciclo hidrológico no centro-oeste do estado de Santa Catarina é abastecido pela evaporação das águas do Oceano Atlântico e pela reciclagem da umidade continental. Sendo que o volume anual da precipitação está intimamente relacionado à atuação dos mecanismos atmosféricos, que transportam e ascendem a umidade.
Consequentemente, os maiores volumes da precipitação anual estão relacionados à eficiência desses mecanismos como, por exemplo, CCMs, sistema de moção e frentes (Grimm, 2009).

Como já mencionado no inicio no presente trabalho embora as chuvas sejam bem distribuídas e não haja um período de seca definido, não há grande variação nos valores totais, apresentando amplitude anual de 426,5 $\mathrm{mm}$. Muito, por influência dos padrões de relevo que se apresentam, variando de escarpas a leste, nos municípios de Urubici e Bom Retiro, para um padrão de relevo de interflúvios médios e amplos para oeste nos demais municípios. Cabe ressaltar que o relevo do alto e médio rio Canoas não apresenta influência orográfica significativa nas precipitações. No entanto, pode-se atribuir à influência dos Complexos Convectivos de Mesoescala os totais pluviométricos mais altos e uniformes identificados no centro-oeste da bacia hidrográfica do rio Canoas. Este dado pode ser verificado na Tabela 2, o qual aponta o mês de outubro com a média máxima da região, seguido pelos meses de setembro janeiro e fevereiro respectivamente.

A espacialização mensal, realizada a partir do método de interpolação IDW, permite identificar no primeiro trimestre, de janeiro a março (Figura 4), as médias mensais mais altas na região leste, onde a estação pluviométrica Urubici registra no primeiro mês uma média de $183,1 \mathrm{~mm}$, bem como a de São José do Cerrito a oeste.

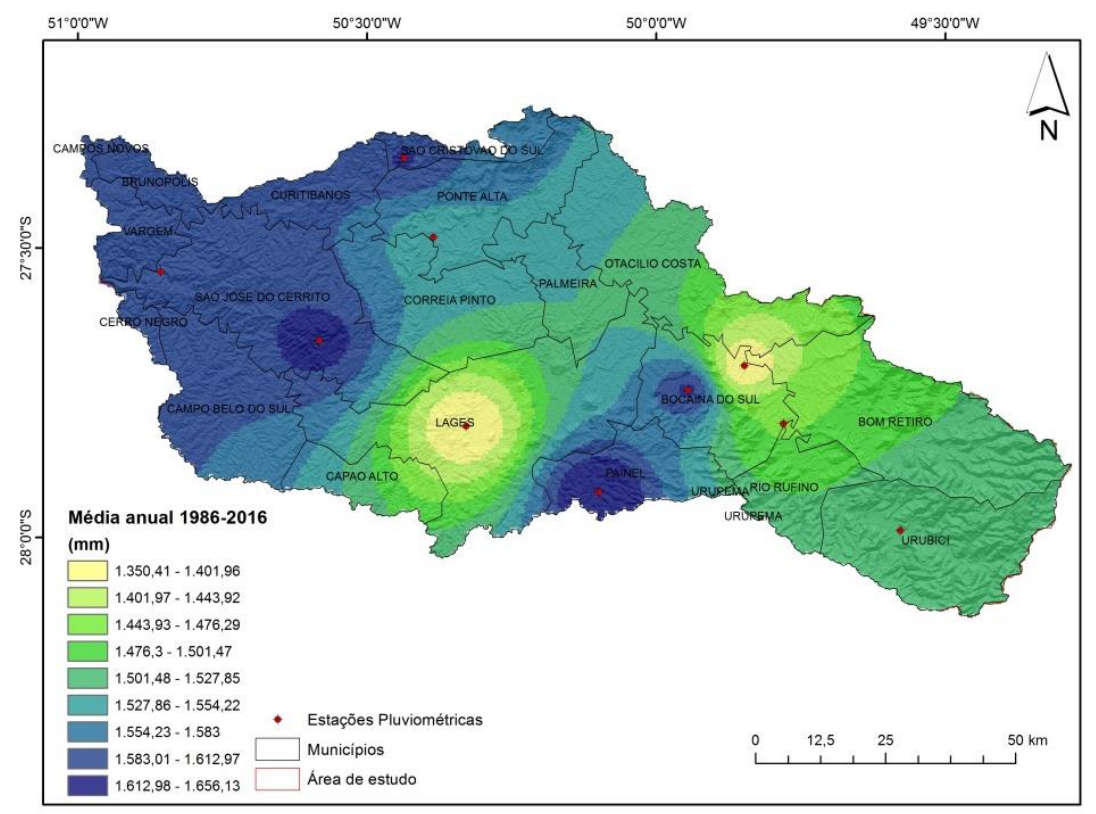

Figura 3. Média anual 1986-2016. Fonte: Agência Nacional de Águas - ANA (2016). 
Em fevereiro este padrão de distribuição de chuvas se mantem, embora haja baixa redução no valor máximo de precipitação, registrando média de $165,3 \mathrm{~mm}$ também na região da estação de Urubici a leste. Esse padrão de distribuição de chuvas está intimamente ligado ao regime subtropical de monção que influência a região nos meses de verão.
O mês de março demonstra um inicio de modificação no padrão de chuvas, onde as médias reduzem tanto no leste quando no oeste da região, e as médias máximas situam-se na região das estações Bocaina do Sul (centro) e Ponte do Rio Antinhas (nordeste) variando entre 118,2 a $123,5 \mathrm{~mm}$.

Tabela 2. Estatística descritiva das médias mensais das estações pluviométricas nos anos de 1986 a 2016.

\begin{tabular}{lllllll}
\multicolumn{1}{c}{ Mês } & \multicolumn{1}{c}{$\begin{array}{c}\text { Desvio } \\
\text { Padrão }\end{array}$} & Média & Máxima & Mínima & Amplitude & $\begin{array}{c}\text { Coef. de } \\
\text { Variância (\%) }\end{array}$ \\
\hline Janeiro & 14,4 & 169,3 & 190,0 & 141,6 & 48,4 & $8,53 \%$ \\
Fevereiro & 12,3 & 148,6 & 166,0 & 121,6 & 44,4 & $8,33 \%$ \\
Março & 6,7 & 111,7 & 127,6 & 101,2 & 26,3 & $6,02 \%$ \\
Abril & 12,7 & 111,1 & 134,2 & 88,2 & 46,0 & $11,47 \%$ \\
Maio & 14,6 & 115,7 & 89,6 & 133,4 & 43,8 & $12,66 \%$ \\
Junho & 13,5 & 111,2 & 134,7 & 85,3 & 49,3 & $12,14 \%$ \\
Julho & 10,7 & 120,9 & 143,8 & 98,4 & 45,3 & $8,86 \%$ \\
Agosto & 8,4 & 96,5 & 117,6 & 85,8 & 31,8 & $8,79 \%$ \\
Setembro & 13,5 & 151,5 & 185,0 & 129,3 & 55,7 & $8,95 \%$ \\
Outubro & 22,3 & 173,8 & 222,2 & 135,8 & 86,4 & $12,84 \%$ \\
Novembro & 11,9 & 121,9 & 144,5 & 98,6 & 45, & $9,80 \%$ \\
Dezembro & 12,8 & 129,5 & 153,1 & 106,2 & 46,8 & $9,92 \%$ \\
\hline
\end{tabular}
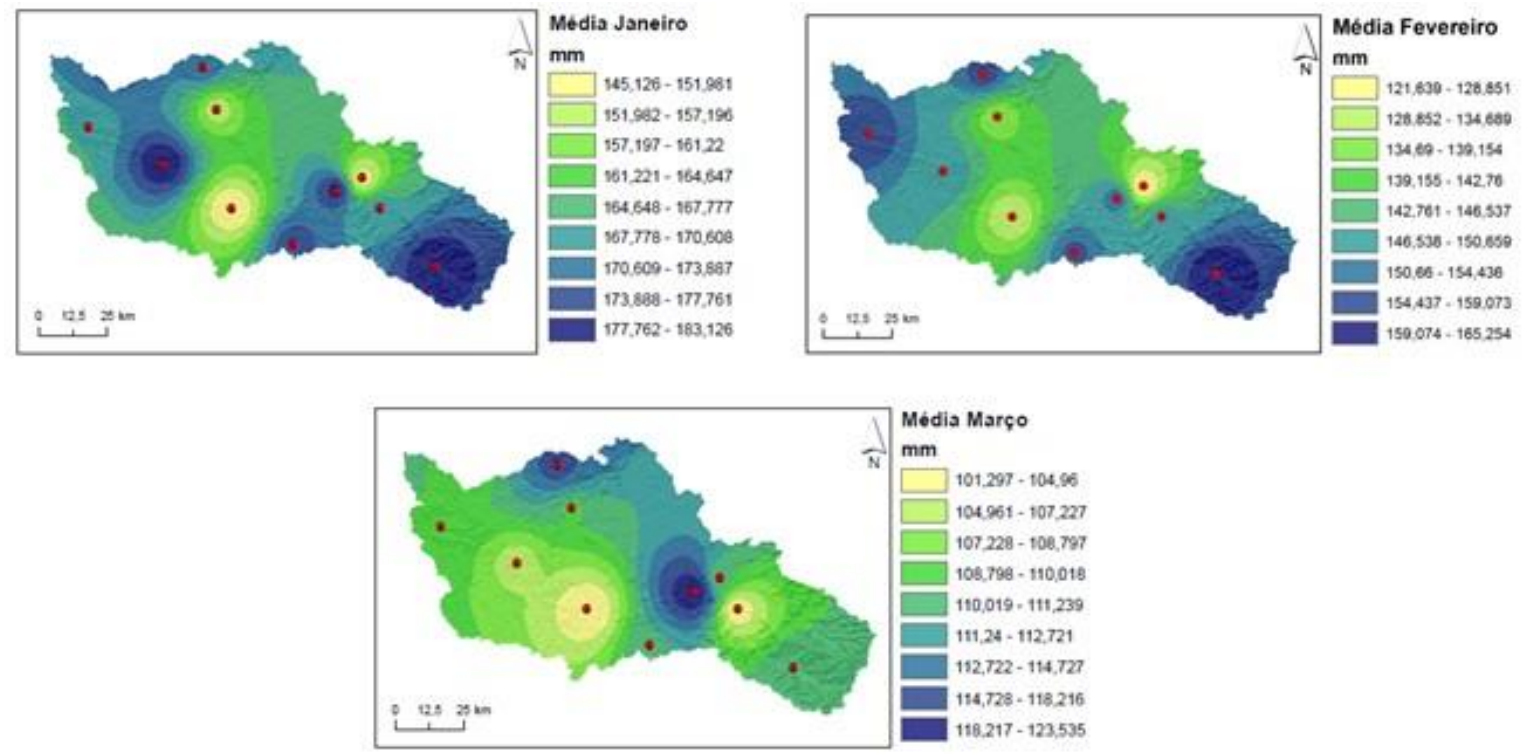

Figura 4. Média mensal de precipitação no período 1986-2016. Meses de janeiro, fevereiro e março. Fonte: Agência Nacional de Águas - ANA (2016).

No segundo trimestre, o qual compreende os meses intermediários de estação de outono, abril, maio e junho (Figura 5) de maneira geral as médias máximas na região não ultrapassam $135 \mathrm{~mm}$. Este período é caracterizado pela transição de leste para oeste nos máximos de chuvas, onde o sistema de monção perde força e inicia a influência das frentes vindas do sul e dos complexos convectivos de mesoescala. Em geral não há grande influência do relevo, o que também contribui para baixa amplitude nos valores. Cabe dar destaque que no mês de junho ocorre mudança de outono para inverno, embora a média máxima varie entre 115 e 
$120 \mathrm{~mm}$, essa chuva abrange uma área maior no oeste da área de estudo.

Dos meses de inverno até o inicio da primavera, julho, agosto e setembro é possível perceber com base na Figura 6, que o mês de julho é bastante influenciado pelo sistema de frentes vindo do sul, onde na estação pluviométrica de Bocaina do Sul é registrado o máximo de precipitação, com a média variando de 137 a $143 \mathrm{~mm}$. No oeste destaca-se uma área homogênea com registro de precipitação entre 121 e 125 mm/mês. Como já mencionado, até mesmo no inverno onde os índices de chuva são mais baixos não se apresenta uma estação de seca. No mês de agosto registram-se mínimas entre 86 a 91 $\mathrm{mm} / \mathrm{mês}$ no oeste, no centro e no leste da área de estudo. Sendo este, o mês com menor precipitação registrada ao longo da análise entre os anos de 19862016.
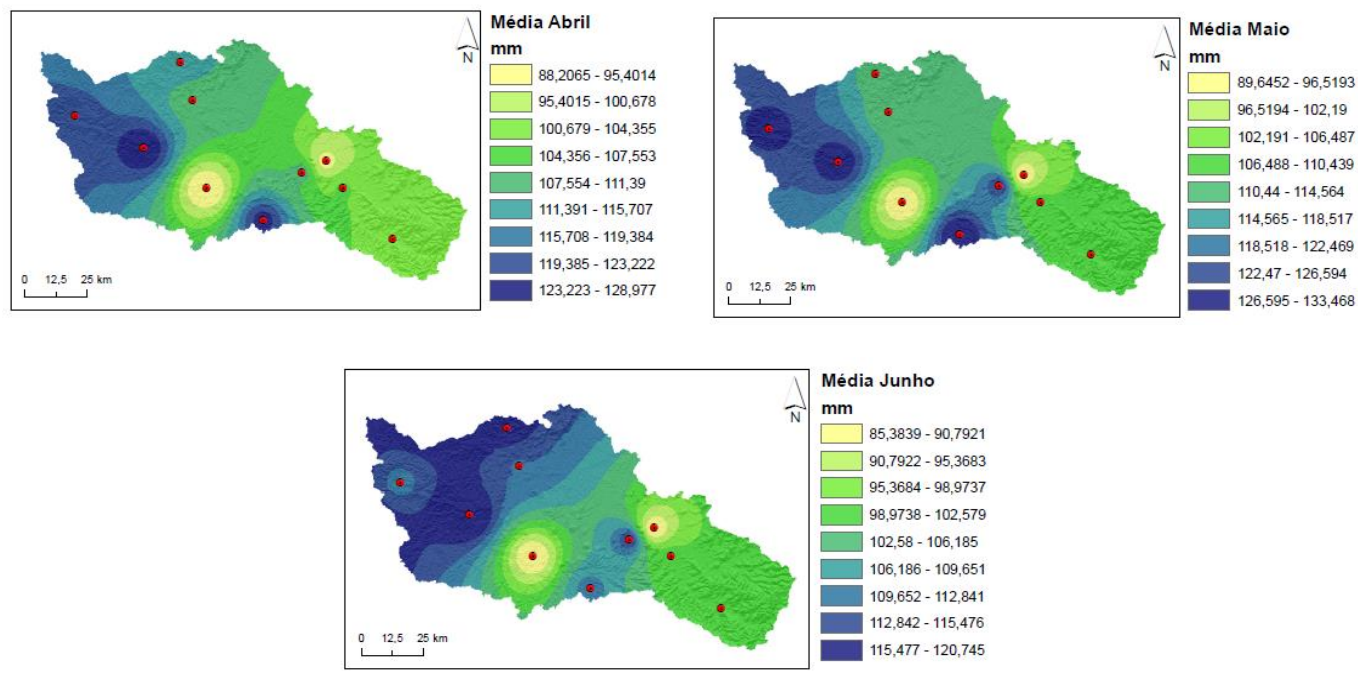

Figura 5. Média mensal de precipitação no período 1986-2016. Meses de abril, maio e junho. Fonte: Agência Nacional de Águas - ANA (2016).
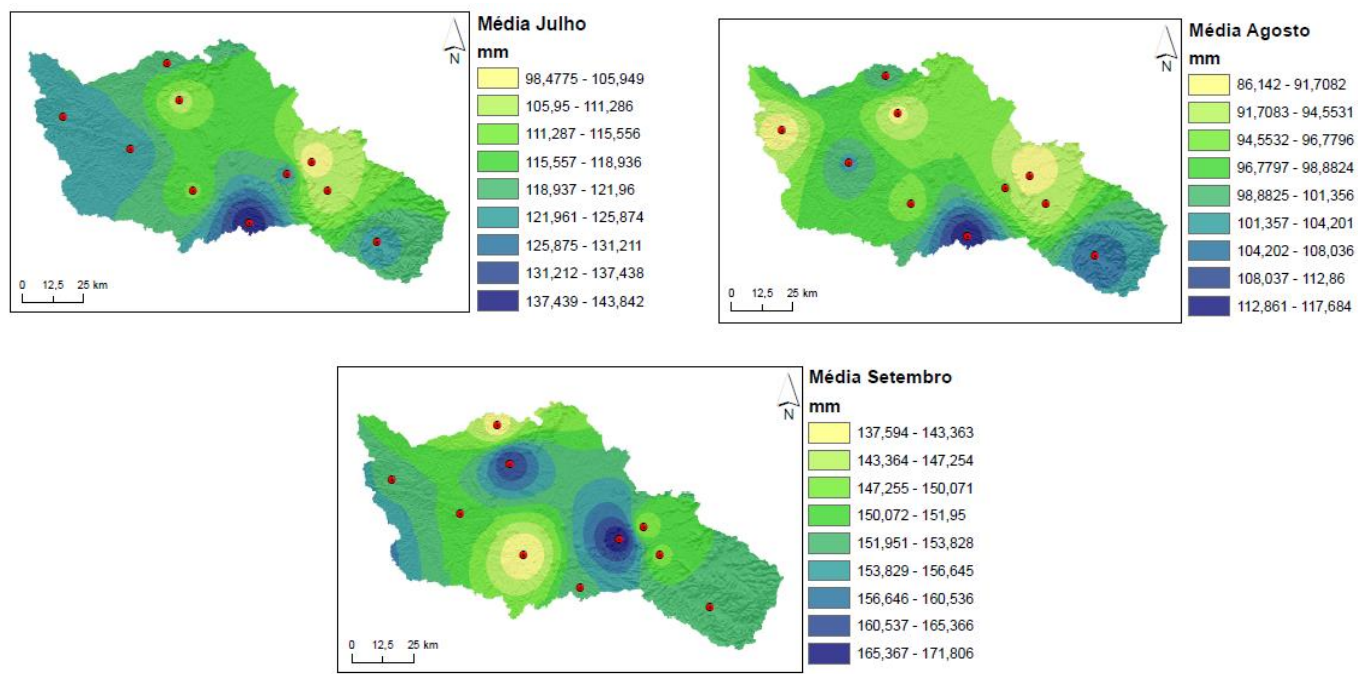

Figura 6. Média mensal de precipitação no período 1986-2016. Meses de julho, agosto, setembro. Fonte: Agência Nacional de Águas - ANA (2016). 
No período de transição, de inverno para primavera, o mês de setembro retoma as altas pluviométricas da região, sob grande influência dos complexos convectivos de mesoescala, aos quais começam se instalar no oeste esta nesta época do ano, apresentando o máximo de influência no trimestre a seguir. Ainda conforme a figura 5, em setembro os picos de precipitação ocorrem no centro da área de estudo, em regiões mais vinculadas a morfologia da depressão periférica.

No último trimestre, em outubro, novembro e dezembro, concentram-se os valores mais elevados de precipitação do ano. É neste período em que os CCMs, influenciam na concentração de chuvas na área de estudo. De acordo com a Figura 7, começando em outubro já é possível perceber na região oeste médias que variam entre 160 a $190 \mathrm{~mm} / \mathrm{mês}$ e cabe destacar o valor mínimo registrado de $141 \mathrm{~mm}$ na estação pluviométrica de Urubici no leste.
Mesmo sendo o menor valor da região ainda é superior as mínimas dos demais meses do ano. Segundo Zipser et al. (2006), a região oeste de Santa Catarina é uma das regiões de mais fortes tempestades no globo. Esses CCMs estão presentes tanto no verão como nas estações de transição, quando seu papel é até mais importante na precipitação, como é possível constatar na localização dos máximos de precipitação nessas estações, e contribuem significativamente para os totais anuais de precipitação (Figura 2). Em novembro os valores apresentados demonstram uma queda na precipitação, pois é um mês de transição entre a influência dos CCMs para o sistema de monções do verão. O qual se apresenta na figura 6 no mês de dezembro no norte/noroeste da região, onde os registros pluviométricos são de até $155 \mathrm{~mm}$.
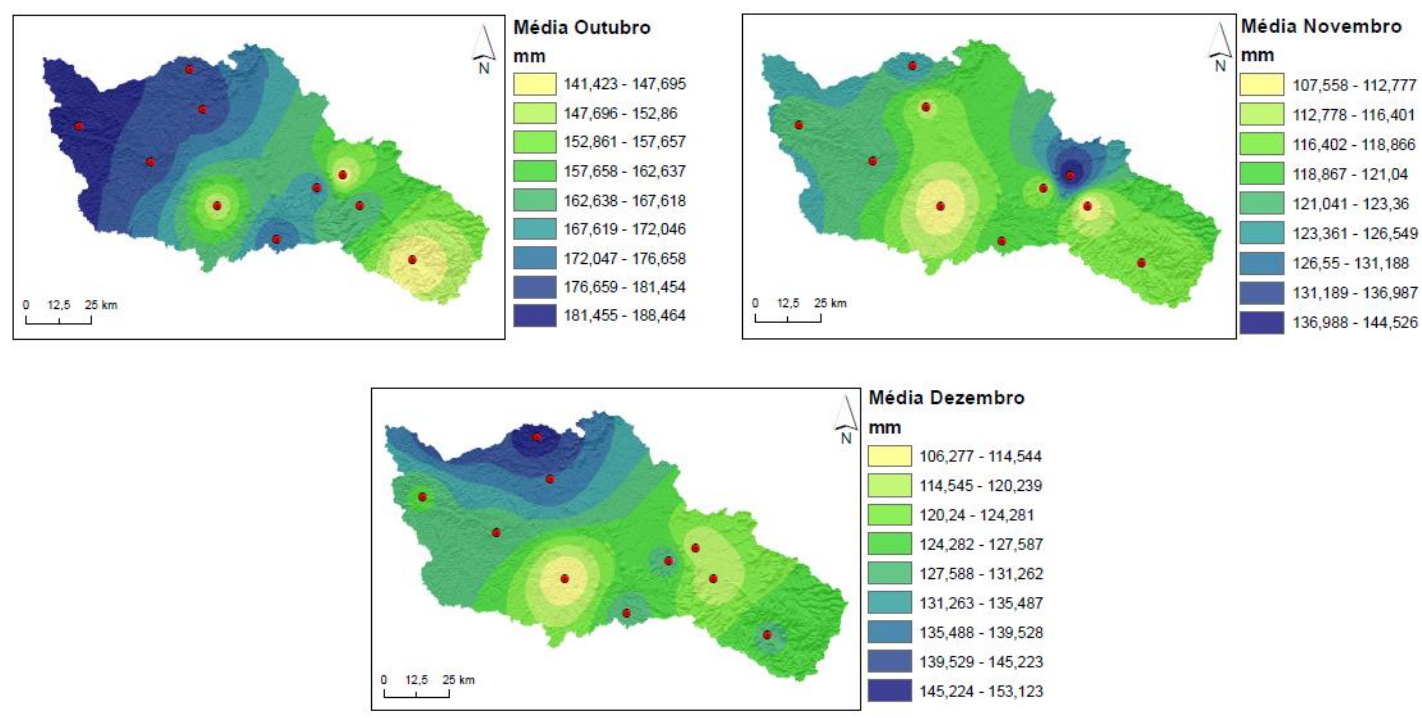

Figura 7. Média mensal de precipitação no período 1986-2016. Meses de outubro, novembro, dezembro. Fonte: Agência Nacional de Águas - ANA (2016).

\section{Conclusão}

O sul do Brasil é caracteristicamente uma região de transição atmosférica e por isto sofre influência de diversos fatores ambientais. O estado de Santa Catarina especificamente caracteriza-se por apresentar mudança ao longo do ano de leste para oeste nos picos de precipitação diferenciandose dos estados limítrofes. Como a área selecionada para o presente estudo está situada no centro do estado é possível observar a influência de três sistemas atmosféricos principais na precipitação, o sistema de monção, o qual eleva os valores da precipitação no leste da área de estudo principalmente nos municípios de Urubici e Bom Retiro, os complexos convectivos de mesoescala, que elevam os padrões de precipitação no centrooeste principalmente nos meses de primavera, e por fim as frentes vindas do sul, as quais influênciam no total das precipitações nos meses de inverno.

A espacialização desses padrões e compreensão das dinâmicas presentes são importantes para o monitoramento e identificação de anomalias no comportamento pluviométrico da região, auxiliando tanto na agricultura como no planejamento/aproveitamento territorial.

\section{Agradecimentos}

Ao CNPq pelo financiamento da presente pesquisa. À Capes pela concessão da bolsa de doutorado e ao 
Programa de Pós-Graduação em Geografia da UFRGS pela estrutura disponibilizada.

\section{Referências}

Amorim. R. C. F.; Ribeiro, A.; Leite, C. C.; Leal, B. G.; Silva, J. B.G. 2008. Avaliação do desempenho de dois métodos de espacialização da precipitação pluvial para o Estado de Alagoas. Acta Scientiarum Technology 30, 8791.

BIgarella, J. J. et al. 2007. Estrutura e origem das paisagens tropicais e subtropicais, 2 ed. UFSC. Florianópolis.

Browing, K.A. 1986. Conceptual models of precipitation systems. Meteorological Magazine $\quad 114 . \quad$ Disponível: https://journals.ametsoc.org/doi/pdf/10.1175/1 5200434\%281986\%29001\%3C0023\%3ACMO PS\%3E2.0.CO\%3B2, 293-319. Acesso: 15 out. 2017.

Caruso, C.; Quarta, F. 1998. Interpolation methods comparison. Comp. Math. Appl., Amsterdam 35. Disponível: https://doi.org/10.1016/S08981221(98)00101-1. Acesso: 10 out. 2017

Ely, D. F. 2006. Teoria E Método Da Climatologia Geográfica Brasileira: Uma Abordagem Sobre Seus Discursos E Práticas. Tese (Doutorado). Presidente Prudente, UNESP.

Fernandes, K.A. 1996. Cavados invertidos na região central da América do Sul. Tese (Doutorado). São José dos Campos, INPE.

Grimm, A. M. 2009. Clima no Sul do Brasil, in. Cavalcanti, I.F de A; Ferreira, N.J; Silva, M.G.A.J da; Dias, M.A.F da S. Tempo e Clima no Brasil. Editora Oficina de Texto, São Paulo, pp.258-276.

IBGE. Instituto Brasileiro de Geografia e Estatística, 2010. Atlas do Censo Demográfico 2010. Disponível: https://censo2010.ibge.gov.br/apps/atlas/. Acesso: 08 jul. 2017.

Kousky, V.E.; Cavalcanti, I.F. 1984. Eventos Oscilação Sul - El Niño: características, evolução e anomalias de precipitação. Ciência e Cultura 36(11), 1888-1889.

Kousky, V.E.; Ropelewsiki, C.H. 1989. Extremes in the Southern Oscillation and their relationship to precipitation anomalies whith emphasis on the South America region. Revista Brasileira de Meteorologia 4, 351-363.

Maddox, R.A. 1980. Mesoscale Convective Complexes. Bul Amer Meteorol Soc 61. Disponível: https://doi.org/10.1175/15200477(1980)061<1374:MCC>2.0.CO;2. Acesso 08 jul. 2017.

Maddox, R.A. 1983. Large-scale meteorological conditions associated with midlatitude, mesoscale convective complexes. Mon Weather Rev $111 . \quad$ Disponível: https://doi.org/10.1175/15200493(1983)111<1475:LSMCAW>2.0.CO;2. Acesso 08 jul. 2017.

Maier, E. L. B.; Costi, J.; Barreira, S.; Simões, J. C. 2016. Precipitações na América do Sul: médias climáticas e padrões da variabilidade no período entre 1979 e 2008. Revista Brasileira de Geografia Física v.9, n.01. Disponível; https://periodicos.ufpe.br/revistas/rbgfe/article/v iew/233674. Acesso: 04 jun.2017.

Marcuzzo, F.F.N.; Andrade, L.R.; Melo, D.C.R. 2011. Métodos de interpolação matemática no mapeamento de chuvas no estado do Mato Grosso. Revista Brasileira de Geografia Física, v.4. Disponível: https://periodicos.ufpe.br/revistas/rbgfe/article/v iew/232714. Acesso: 04 jun. 2017.

Monteiro, C. A. de F.. 1971. Análise ritmica em climatologia: problemas da atualidade climática em São Paulo e achegas para um programa de trabalho. Climatologia 1. Disponível: http://bdpi.usp.br/item/001349819. Acesso: 07 mai. 2017.

Monteiro, C. A. F. 1976. Teoria e clima urbano. Séries Teses e Monografias 25. Instituto de Geografia da USP, São Paulo.

Vera, C.; Baez, J.; Douglas, M.; Emmanuel, C. B; Marengo, J.; Meitin, J.; Nicolini M.; NoguesPaegle, J.; Paegle, J.; Penalba, O.; Salio, P.; Saulo, C.; Silva Dias, M. A.; Silva Dias, P.; Zipser, E. 2006. The South American Low-Level Jet Experiment. American Meteorological Society $87 . \quad$ Disponível: https://journals.ametsoc.org/doi/pdf/10.1175/BA MS-87-1-63. Acesso: 04 jun.2017.

Oliveira, A. S. 1986. Interações entre sistemas na América do Sul e convecção na Amazônia. Dissertação (Mestrado). São José dos Campos, INPE.

Pandolfo, C.; Braga, H. J.; Silva, JR, V. P. da; Massignam, A. M., Pereira, E. S.; Thomé, V. M. R.; Valci, F.V. 2002. Atlas climatológico digital do Estado de Santa Catarina. Florianópolis: Epagri. CD-Rom.

Rossato, M. S. 2011. Os climas do Rio Grande do Sul: variabilidade, tendências e tipologia. Tese (Doutorado). Porto Alegre, UFRGS.

Ropelewsiki, C.R.; Halpert, S. 1987. Global and regional scale precipitation patterns associated with the El Niño/Southern Oscillation. Mon. Weather Rev 115, 1606-1626.

Sant"Anna Neto, J. L. 1998. Clima e organização do espaço, in: Boletim de Geografia n.16. Disponivel: 
Revista Brasileira de Geografia Física v.11, n.04 (2018) 1264-1274.

http://www.periodicos.uem.br/ojs/index.php/B olGeogr/article/view/12158. Acesso 7 jul.2017. http://dx.doi.org/10.4025/bolgeogr.v16i1.1215 8

Scolar, J.; Figueiredo, J.C. 1990. Análise das condições inóticas associadas à formação de Complexos Convectivos de Mesoescala, in: VI CONGRESSO BRASILEIRO DE METEOROLOGIA, CBMET, Anais 2, 457 461.
Velasco, I.; Fritsch, J.M. 1987. Mesoscale Convective Complexes in the Americas. Journal of Geophycal Research 92. Disponível: https://agupubs.onlinelibrary.wiley.com/toc/215 62202d/1987/92/D8. Acesso: 10 out.2017.

Zipser, E.J.; Cecil, D. J.; Liu, C.; Nesbitt, S.W.; Yorty, D.P. 2006. Where are the most intense thunderstorms on Earth? Americal Meteorological Society 87. Disponível: https://journals.ametsoc.org/doi/abs/10.1175/BA MS-87-8-1057. Acesso: 04 jun.2017. https://doi.org/10.1175/BAMS-87-8-1057 